\title{
Engaging The Narrative On Children Literature Through The Teaching Extensive Reading
}

\author{
Imron Wakhid Harits \\ Stefan Chudy
}

\begin{abstract}
Teaching children literature engages with some of interconnected aspects such as psychology and the literature as well. Such connection represents the emotional and intellectual interaction during the process of teaching and learning children literature. The method for example the approach tries intertwining and supporting during the process of teaching and learning. The life experiences of the reader and the prior knowledge are essential in the teaching of children literature because an intellectual and emotional connection need reconstruct their prior knowledge and experiences to get the new preposition in understanding the children literature texts. This paper examines the teaching children literature in the extensive reading class and its interaction with historical and educational values as well as its literary devices. It also figures aout the process of the readers using their cultural and tradition experiences to engage with the children literature. The terms of engagement is derived from Nikolajeva cognitive criticism, it is the ways of readers how to understand the children literature from inside and outside communication.
\end{abstract}

Keywords: teaching children literature, emotional and intellectual connection, constructivism

\section{INTRODUCTION}

The notion of children literature closely connected with the term of education such as the didactic. When the children literature analysis emphasizes on the text, the children literature in the education context stresses on the readers. It is not simply problem to bring the children literature in the education context. Some aspects of psychology have to been considered by the teacher. For examples, age of the learners, the social and cultural background of the learners, and the content of the stories. The learners with the different age should get the different level of the stories because they also have the different level of capability both emotionally and cognitively. Piaget concept of the cognitive development level supports to the teachers before the stories are given and shared into the class. Further not all the stories that will be given to the learners are appropriate for the learners, such as in some religious area the stories (Snow White, Cinderella) are too vulgar. Through some of social history understanding the teacher could give an appropriate story for the learners. The content of the story somehow is also subversive and cruel hereby the teacher has to use it as the main consideration either.

The reading activities such as reading children literature obviously leads the learners coming to the deeper process dealing with the psychology, cognitive and literature. Practicing the close reading of children literature consequently the learners carry out the literature analysis. They observe and examine some aspects of narrative in the text. The learners could not neglect the narrative structure if they want to comprehend the content of the children literature text. Like in the Jack Tales and the Giant Slayer, The learners have to know the main character, who is the hero? Who is the trickster? What kind of the setting? and how is the plot ? Such questions are definitely urgent when the learners practice the close reading with children literature as the 
material's provision. For example the understanding of the plot as the series of event in the story should be as of the primary competence in the close reading for children literature. When analyzing the plot the learners involve with the story, she deserves their time to engage with the hero/heroine for an instance. The learners somehow will be entrapment in the predicament like the hero during the crisis.

Reading children story such as the Donkey Skin can make the readers somehow feel like the heroine/ the princess who disguise as the servant. The readers feel the hard struggle, intimidation, and worried if her disguise will be uncovered on the other hand, the readers' feeling are happy when the princess was accomplished some of her tasks. That's all the emotional feeling when we study the children literature and practice it using the close reading. Learning children literature hereby is the process of intellectual activity and emotional connection. During the process of intellectual the readers could analyze some of figurative language such as the metaphor, symbol, and irony. The readers should come to the findings of literature aspects using some of strategies otherwise it will not be working without the involvement of the emotional domain. The readers usually connect all the stories with their life experiences and prior knowledge. In this notion the constructivism method in learning could be applied to get the literary engagement for the readers.

\section{Psychological Context in Learning}

\section{LITERATURE REVIEW}

In relation to the folktales/fairy tales as practiced in the classroom it is salient exploring the learner's curiosity of what is the content, how is its historical background, what kinds of the literature aspects etc. According to the principles of constructivism that is applied in teaching folktales/children stories, Ausubel (1968) proposes the mental scaffolding to obtain the new information. Vigotsky then develop the cooperative learning to engage some of supporting elements in teaching aspects. The Vigotsky concept of scaffolding is developed by Donna Ogle with the K-W-L technique. It is the way of the teacher exploring the learner's prior knowledge. It is suitable with the principle of scaffolding, putting it all together.

Further dealing with cognitive psychology, this concept was born as the response to the behaviorism theory which is judged only focusing on behavior and neglected the mental process of the learners. Cognitive Psychology focuses on the study of how people think, understand, and know. They emphasizes on learning how people comprehend and represent the outside world within them selves and how our ways of thinking about the world influence our behavior. For cognitivist, the students are not only "tabula rasa", or empty glass who getting their knowledge from their parents and teachers, but they also actively construct their own knowledge. The process of construction is affected by their engagement with the environment and their own experiences, although its construction will be different according to their age. The salient factors in producing the cognitive development are nature and nurture. The nature relates with the maturation of brain and body, and the nature will affect to the ability to perceive, learn, act, and motivation. On the other hand, nurture divides into two type, organization and adaptation. An organization refers to Children integrate particular observations into a body of coherent knowledge. Then, in adaptation, the children respond to the demands of the environment in ways that meet their own goals.

This theory tries to combine between behaviorism, cognitive development theory, and its environmental influences. Based on this theory, the people basically observe other people behavior, and they store it in their mind, then they will perform the new behavior. This theory is happened in the social context, the people learn another, by modeling and imitation. This is also called 
observational theory, because in modeling and imitating, there is happened the process of observation from one to another. Bandura is the proponent of this theory, according to Bandura (1977) learning would be exceedingly laborious, not to mention hazardous, if people had to rely solely on the effects of their own actions to inform them what to do. Fortunately, most human behaviour is learned observationally through modeling: from observing others one forms an idea of how new behaviours are performed, and on later occasions this coded information serves as a guide for action. Social learning theory explains human behavior in terms of continuous reciprocal interaction between cognitive, behavioural, an environmental influences. There are four components in line with the process of underlying observational learning namely: Attention, Retention, Motor Reproduction and Motivation.

\section{Narrative Approach in Children Literature}

Literary approach of the children literature examines the stylistics features and the thematic significance of the tale of genre and its historical development. Adopting from the new criticism theory, Max Luthi suggested examining the form and the structure of the folktales/fairy tales as the unity. Luthi in Zipes (2000) argued fairy tales contain essential underlying meanings which, in so far as form and meaning are thought of as integral, are manifest in the basic style of the fairy tale (p.18). Luthi examines the tales' motif and the story elements for instance plot, character, characteristics, setting, figurative languages, theme etc. and ignores the social and cultural context of the story. Like the principles of the new criticism, Luthi approach of the folktale/fairy tale ranges from the specific features to the general. The analyzing of the particular elements points to the general meaning and the understanding of the stories' genre. Further Luthi in Zipes (2000) stated specific features are discussed in so far as they are typical of the genre and can be used to assert abstract general ideas (p.18). This approach begins with the textual close reading then it will interpret and observe its form and literary elements. Hence, the folktales/fairy tales here are not from the oral tradition but literary tradition.

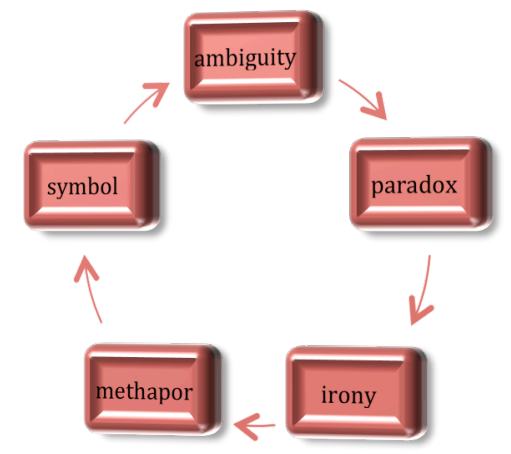

Figure 1: the cycle of literature analysis

Further Gould (2003) states that a well - developed story should have character, setting, plot, complication ( tension, problems, conflict), crisis, and resolution. All of these elements must be integrated in one story, because such elements will attract the reader or the audience while they read or listen the story. The folklores should pay attention to such elements too, because if it only focuses on the content, although it is full of moral message, it will not attract the young generation to read or listen the story. Therefore, the writer and the story teller must develop and express their imagination maximally to create and modify the story, so that it become the interesting story. In line with this phenomenon Lavid (2008) states that story is created from the imagination of a writer, who in turn must translate it onto a page of symbols so that another person can read, absorb, and experience the story in a similar fashion. Then, Kincaid in Fitzpatrick (2005) gives a definition about a good narration, he tells that a good narration are pleasure to read because they have a sequence of events to follow, descriptive details, and characters whose feelings we can appreciate. 
The writer and story teller should attend to the structure story in developing the story, they should overcome and develop their competence in creative writing. The skills in relation with the creative writing while they retell or rewrite the story are intuitive thought, creative and imaginative feeling, and controlled emotion.In addition Lavid (2008) gives her opinion about the qualifications and competences in writing fiction, she tells that fiction demands a working knowledge of many points of craft. And while mastering craft can be daunting, each one of us has skills to meet the challenge. If you have an analytical mind, cause and effect will be solid. If you are intuitive, your story will take imaginative twists. If you are emotional, you will have a true internal compass to tell a riveting story. If you are a global thinker, you will see the whole. If you are a detail person, your story will be tight. If you are a visual, auditory, or tactile person, your story will be vivid. If you are curious, writing will never bore you. If you are empathic, your characters will be believable. If you're old, you'll bring a wide array of experience into the process. If you're young, your story will be fresh. If you're stubborn and relentless, your story, at last, will be finished. Due to every competences and talent are being appreciated, as a result the creative writing problems, especially to write and retell a story, both of prose and folklore are not the complicated problem anymore. It means that everyone can undergo to write the story. Thus, the way of creative writing including prose and folklore can be taught and learnt

\section{RESEARCH METHOD}

1. To examine and observe of children literature learning in the classroom with its narrative approach always dealing with the literary history, literary biography, and social history. The researcher as the key instrument carries out the participant - observation with the informal method of note-taking. The ethnography research is appropriately applied due to its way of the data collection that refers to the history and culture. In associated with the research, it remarked that doing ethnography as the collection of data that describe a culture (Bernard, 2004, p. 16). Then, the data collection uses the participant - observation method to record the data and to obtain the adequate information. On account of its comparison of the two different viewpoints between the learners cultural and Education contexts, the ethic perspective enables to observe the multi - cultural views from the different context. Because ethic perspective is associated with the comparison of differing cultures and populations enables researchers to develop broader cross cultural themes and concepts (Morris et als., 1999).

\section{DISCUSSION}

\section{The Children Literature Narrative Process in Teaching Reading}

The connection between the children literature and education is like two edges of the sword, it tightly connected and both of them have an important function. The children literature obviously is used as the media in teaching and conveyed the moral, cultural and historical values to the readers. Children literature notion studies many aspects of art as its substantial element in literature such as motif, metaphor, symbol and illustration as well as its socio - cultural and historical background that accompany the children literature. Learning children literature employs two consequences first it is as the mirror, where the readers reflect themselves in the story and through the characters in the folktales/fairy tales. Or, it is as the window, it means that the children literature uses as the gate for exploring the world and searching their own experiences in acquaintance with the social, cultural and tradition. Nikolajeva remarked ( 2014 ) It is trivial to state that children literature's has throughout history been employed as an educational vehicle (p.2).Not only in the didactic but also in the education domain in general, the children literature has given myriad contribution for educational values such as searching of national identity, cultural awareness, and moral. 
On the other hand, in children literature, we also learn other aspects connected with education such as psychology of education based on the characters of the story and its conflicts. The vicarious experiences as the effect of psychology are one of the concerns in education. While the focus of the literary folktales/fairy tales somehow is different with education otherwise it could be unified. The literary folktales/fairy tales emphasizes on the text research and the education purpose definitely stresses on the readers. Then, should the didactic and text split? Surely it is silly idea to split both because each of them supports each other in the way of education, while the readers analyze and probe some important points they have to investigate some literary aspect in children literature.

The communication in children literature is imbalance if it refers to the author context and its relationship with the readers. This notion has some implications connected with the educational dimension in children literature. For example one of the Perrault fairy tales, Little Red Riding Hood, it has been adapted in some versions because of the readers consideration. It is too subversive for the children and show up the sexuality. In one parts of this fairy tale, the girl was asked to have the striptease dance by the wolf. It is inappropriate part that in the forthcoming issue was modified. In line with the relationship between the author and the reader in children literature Nikolajeva (2003) stated that one of the essential characteristics of children's literature is the cognitive gap between the adult and the child reader pinpointed through the widely accepted concepts of single, double, and dual address (p.6). The children literature hereby pops up the reflexive question, what is being told? and how is told? These two questions indicate two different points. First it focuses the reader context, the author has to consider the age and level of reader's cognitive ability. The cognitive theory from Piaget could be used as the consideration while the works are written. Then, the second question stresses on the narrative aspects such as characterization, symbol, and metaphor as well as the socio - cultural background and history of folktales/fairy tales.

Further Nikolajeva (2014) suggested the concept of the engagement in the teaching and learning of children literature. Her concept is closely linked with the cognitive and emotional aspects of the children literature readers, it is not merely what they understood from the story but it has the connection with an aesthetic pleasure that the readers got from the children literature texts. The engagement itself carries out within two types, the comprehension and the response. This is originated from the Cognitive theory from Skinner about the interconnection of stimulus-responsereinforcement. The comprehension according to Nikolajeva (2014) involves the ability to make meaning of texts on the level of contents. While the response refers to readers' reaction toward the provoked or unintentional encounter with the text; a signal that the reader has received the message (p.2). The cognitive theory thus emphasizes on the interaction between the readers and works of children literature as well as the text construction. The interconnection between the cognitive (intellectual) and the emotional is also suggested by Dianne M. Barone (2004). The particular book somehow could lead the reader exploring more of knowledge and not only reading activity. The readers could learn beyond the reading activity such as trying to analyze the figurative language, symbol, and probably the illustration of the texts. In line with this notion, Barone advocates the literary engagement, it is the intertwining of emotion and intellect are, in essence, what drive literary engagement (p.3). The process of learning children thus strongly associated with psychological process of learning and the social process in another side.

The cognitive criticism theory from Nikolajeva is derived from the social constructivist theory in which the works of children literature construct the human cognition through some of the phenomena. The vicarious experiences are the essential point in this cognitive theory. The perception, attention, empathy, memory, reasoning, decision - making, language and learning are some phenomena that have to observed and examined in cognitive theory. Shortly the cognitive criticism is way of thinking about literature (Stockwell, 2002, Nikolajeva, 2014). Being the cognitive 
criticism closely related with the social constructivism, the use of the factual experiences (schemata) and knowledge as well to reconstruct or engage the works of children literature are needed. The social knowledge and experiences of the readers are the key element to comprehend the texts. Such as in some of folktales/ fairy tales from Czech and Slovenia, there were almost all of them show the relationship between the ordinary people (gardener, fisherman, farmer, merchant) married with the noble man (King, Prince, Queen, princess). This story background could be understood through the social knowledge and experiences of the readers. It is interconnected with their history of the country. Czech and Slovenia were under Hapsburg Empire for hundreds year and it has implications to their folktales/ fairy tales. They do not have the long royal tradition because both countries were only part of the huge empire in Europe.

Furthermore the notion of children literature and its activity for analyzing are the process of collaborative learning. Analyzing and discussing of children literature is the syntactical of literature and readers. Wolf (2004) depicted the relationship between children literature and readers as an interaction with literary language implies lifting the words off the page to new levels of creativity, connections, and criticism in collaboration with others (p.285). The notion of children literature hereby the combination process in learning associates with the entire of narrative elements in children literature for an instance plot, theme, symbol, character, characterization, metaphor and other figurative language with the author life. Exploring the author life background involved the social, cultural, and historical point of view. The next, Wolf (2004) argues children learn about authors and close readings, investigating the intersection of the narrative components (genre, theme, character, setting, plot, point of view, style, and tone) and the life of the author behind it (p.285). The readers therefore construct their personal life experiences during the process of children literature learning. The readers try engaging their past experiences and their current experiences to construct the new understanding of children literature texts.

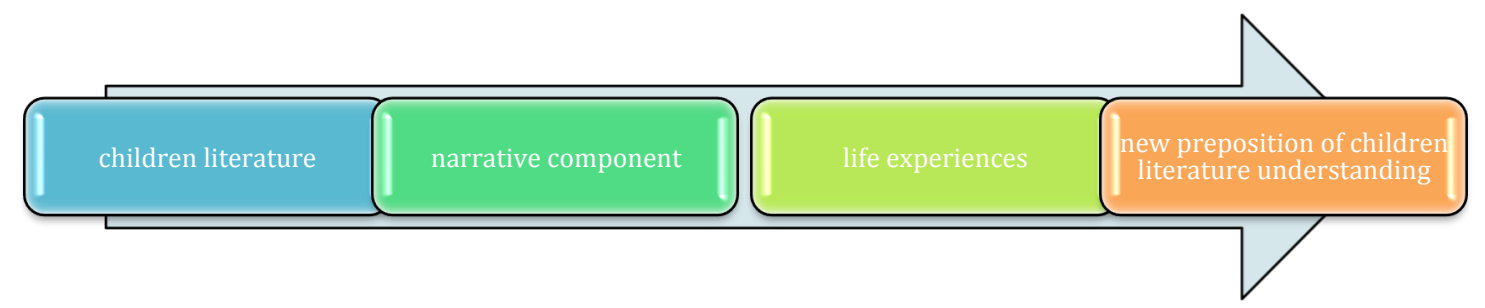

Figure 2: the process of children literature using constructivism

Life experiences contributes a lot for learners to understand the different texts of children literature particularly folktales/fairy tales. The readers internalize some of their experiences, such as their impression within the text with their life experiences and environment. The next phase the readers attempt to apply their life experiences when they have the other texts when they are reading. On contrary, without a sufficient life experiences folktales/fairy tales is not easy to understand. For example, such the metaphor in Snow White depicted her hair as black as ebony it is really hard for the readers who do not know what the ebony is. The ebony tree is the special tree that is only found out in Celebes Island (Indonesia) and in India. This tree could not find in Europe. Or, like the birth of Snow White depicted as white as snow. It takes time and could be wrong to understood and interpreted by the readers in Asia and Africa who do not have an experience with snow during the entire of their life. In this process of learning, the teacher could take the role to give the learning support for the learners. The teacher has to facilitate the learners by designing some of the questions, charts, and other learning equipments to help the learners solving their problem. The teacher supports during the learning process to trigger the learners exploring their life experiences called scaffolding method. 


\section{Inquiring, Exploring and Engaging the Folktales/Fairy Tales through Scaffolding}

Scaffolding as one of an effective way to exploring the learners' life experience within the folktales/ fairy tales, because in this method Vigotsky suggested the cooperative learning or the collaboration among the learners. It enables them sharing their experiences. The scaffolding is a kind of help and support enabling the learners acquiring the knowledge and developing understanding. Pritchard and Woolard (2010) distinguish the approach of scaffolding into two types, first planned intervention, in this type the teacher provides some of materials and instruction for guiding the learners. The teacher designs some of instructions before the class to support the learners during the process of learning. For example in understanding the folktales/ fairy tales, the teacher could provide some of charts to digging the further knowledge of the learners. The sample of chart is K-W-L chart (it will discuss later). The second approach is "ad hoc" intervention. This approach is according to the learner's need and situation. The teacher can take the role to provide some of information associated with the learner's need. Also, the teachers can give some other problem solving from the different viewpoint. Both of the approaches need the deep identification within the problem of the learners during the process of learning. The main purpose of the scaffolding is to achieve the higher level of development through the different approaches. Then in the end of learning process, the teacher gives some of meaningful feed back to the learners.

$\mathrm{K}-\mathrm{W}-\mathrm{L}$ chart is one of the appropriate and overwhelming strategies to inquiry, to explore, and to engage the understanding and comprehending of the learners within the text. The first phase of $K$ or what they Know is the process of brainstorming. The teacher encourages the learners to suggest and explore their opinion of the targeted topic. In the case of folktales/fairy tales comprehending, the teacher could extend the questions in associated with the deeper aspects such as what do you know about the social life? What do you know about the historical context of the tales? What do you know about the authors? During the process of brainstorming, the learners could work independently because the teacher wants to know their real understanding and viewpoint within Czech, Slovenia, and compared with Madura tales. Their own preposition is definitely important as the inquiry process for the basic understanding.

\section{CONCLUSION}

Teaching and learning children literature through the teaching reading particularly the extensive reading gives the two main viewpoints between intellectual activity and the emotional activity. During the process of extensive reading activity the learners try o engage with some of the stories. Hence the narrative components as the device to analyze the children literature texts are the bridge to associate the emotion and the intellectual process in the text analysis and comprehension. The engagement process also needs the reconstruction of the readers' life experiences and the readers' schemata. The involvement of life experiences and prior knowledge leads them to the better and profound understanding of the children literature.

\section{References}

Blachowicz, Camille, Donna Ogle. (2008). Reading Comprehension: Strategies for Independent Learners. New York: Guilford Press

Barone, Diane M. (2011). Children's Literature in The Classroom. New York: Guifold Press

Desforges, Charles in Bob Moon eta als.(ed).2000. Routledge International Companion to Education. London: Routledge

Erben, Karel Jaromir, Bozena Nemcova.2014. Czech Fairy Tales. European Union: Vitalis

Gray, Louis Herbert. (1918). The Mythology of All Races. Boston: Marshall John Company

Grenby, M. 2004. Children Literature. Edinburg: Edinburg University Press. 
Grilli, Giorgia.1997.Myth, Symbol, and Meaning. New York: Routledge.

Hakemulder, Jameljan.2000.The Moral Laboratory. Amsterdam:John Benyamin Publishing

Hasse, Donald. (2008). The Greenwood Encyclopedia of Folktales and Fairy Tales volume 1-3. London: Greenwood Press

Horihan, Margery. 1997. Deconstructing the Hero.London:Routledge.

Hunt, Peter (ed.). 2003. Literature for Children. London: Routledge

Luthi, Max.1982.European Folktale: Form and Nature. Bloomington: Indiana University Press

Lynch-brown, Carol , Carl M. Tomlinson.1999.Essential of Children Literature.Boston:Allyn and Bacon.

Marczyk, Geoffrey, David de Matteo, David Festinger.2005. Essential of Research Design and Methodology. New Jersey: John Wiley and Sons inc.

Nikolajeva, Maria. (2014).Reading for Learning. Amsterdam: John Benjamin Publishing company

Nikolajeva, Maria. Beyond The Grammar of Story, or How Can Children Literature Criticism Benefit from Narrative Theory? Children's Literature Association Quarterly, Volume 28, Number 1,Spring 2003, pp. 5-16. DOI: 10.1353/chq.0.1702

Wolf, Shelby A. (2004). Interpreting Literature with Children. London: Lawrence Erlbaum Associates

Zipes, Jack.(2000). The Oxford Companion to Fairy Tales. New York: Oxford University 